\title{
GC-MS Discrimination of Citrulline from Ornithine and Homocitrulline from Lysine by Chemical Derivatization: Evidence of Formation of $N^{5}$-Carboxy-ornithine and $N^{6}$-Carboxy-lysine
}

\author{
Svetlana Baskal, Alexander Bollenbach and Dimitrios Tsikas *(D)
}

\section{check for} updates

Citation: Baskal, S.; Bollenbach, A. Tsikas, D. GC-MS Discrimination of Citrulline from Ornithine and Homocitrulline from Lysine by Chemical Derivatization: Evidence of Formation of $N^{5}$-Carboxy-ornithine and $N^{6}$-Carboxy-lysine. Molecules 2021, 26, 2301. https://doi.org/ $10.3390 /$ molecules 26082301

Academic Editor: Paraskevas D. Tzanavaras

Received: 24 March 2021

Accepted: 13 April 2021

Published: 15 April 2021

Publisher's Note: MDPI stays neutral with regard to jurisdictional claims in published maps and institutional affiliations.

Copyright: (c) 2021 by the authors. Licensee MDPI, Basel, Switzerland. This article is an open access article distributed under the terms and conditions of the Creative Commons Attribution (CC BY) license (https:// creativecommons.org/licenses/by/ $4.0 /)$.
Core Unit Proteomics, Institute of Toxicology, Hannover Medical School, 30625 Hannover, Germany; baskal.svetlana@mh-hannover.de (S.B.); bollenbach.alex@gmail.com (A.B.)

* Correspondence: Tsikas.dimitros@mh-hannover.de

Abstract: Derivatization of amino acids by $2 \mathrm{M} \mathrm{HCl} / \mathrm{CH}_{3} \mathrm{OH}\left(60 \mathrm{~min}, 80^{\circ} \mathrm{C}\right)$ followed by derivatization of the intermediate methyl esters with pentafluoropropionic anhydride (PFPA) in ethyl acetate (30 $\mathrm{min}, 65^{\circ} \mathrm{C}$ ) is a useful two-step derivatization procedure (procedure A) for their quantitative measurement in biological samples by gas chromatography-mass spectrometry (GC-MS) as methyl ester pentafluoropropionic (PFP) derivatives, $(\mathrm{Me})_{\mathrm{m}}-(\mathrm{PFP})_{\mathrm{n}}$. This procedure allows in situ preparation of trideutero-methyl esters PFP derivatives, $\left(\mathrm{d}_{3} \mathrm{Me}\right)_{\mathrm{m}}-(\mathrm{PFP})_{\mathrm{n}}$, from synthetic amino acids and $2 \mathrm{M} \mathrm{HCl} / \mathrm{CD}_{3} \mathrm{OD}$ for use as internal standards. However, procedure A converts citrulline (Cit) to ornithine (Orn) and homocitrulline (hCit) to lysine (Lys) due to the instability of their carbamide groups under the acidic conditions of the esterification step. In the present study, we investigated whether reversing the order of the two-step derivatization may allow discrimination and simultaneous analysis of these amino acids. Pentafluoropropionylation $\left(30 \mathrm{~min}, 65^{\circ} \mathrm{C}\right)$ and subsequent methyl esterification $\left(30 \mathrm{~min}, 80^{\circ} \mathrm{C}\right)$, i.e., procedure $\mathrm{B}$, of Cit resulted in the formation of six open and cyclic reaction products. The most abundant product is likely to be $N^{5}$-Carboxy-Orn. The second most abundant product was confirmed to be Orn. The most abundant reaction product of hCit was confirmed to be Lys, with the minor reaction product likely being $N^{6}$-Carboxy-Lys. Mechanisms are proposed for the formation of the reaction products of $\mathrm{Cit}$ and $\mathrm{hCit}$ via procedure $\mathrm{B}$. It is assumed that at the first derivatization step, amino acids form $(N, O)$-PFP derivatives including mixed anhydrides. At the second derivatization step, the Cit-(PFP $)_{4}$ and hCit-(PFP $)_{4}$ are esterified on their $C^{1}$-Carboxylic groups and on their activated $N^{\text {ureido }}$ groups. Procedure B also allows in situ preparation of $\left(\mathrm{d}_{3} \mathrm{Me}\right)_{\mathrm{m}}-(\mathrm{PFP})_{\mathrm{n}}$ from synthetic amino acids for use as internal standards. It is demonstrated that the derivatization procedure B enables discrimination between Cit and Orn, and between hCit and Lys. The utility of procedure B to measure simultaneously these amino acids in biological samples such as plasma and urine remains to be demonstrated. Further work is required to optimize the derivatization conditions of procedure B for biological amino acids.

Keywords: amino acids; derivatization; esterification; GC-MS; pentafluoropropionic anhydride; ureide

\section{Introduction}

Analysis of amino acids, dipeptides, and tripeptides such as glutathione by gas chromatography-mass spectrometry (GC-MS) requires suitable derivatization reactions to convert them into volatile and thermally stable derivatives [1-9]. Derivatization of amino acids with $2 \mathrm{M} \mathrm{HCl}$ in methanol $\left(\mathrm{CH}_{3} \mathrm{OH}\right)\left(60 \mathrm{~min}, 80^{\circ} \mathrm{C}\right)$ yields their mono- and di-methyl esters. Subsequent reaction with pentafluoropropionic anhydride (PFPA) in ethyl acetate (30 $\mathrm{min}, 65^{\circ} \mathrm{C}$ ) generates the $\mathrm{N}$ - and $\mathrm{O}$-pentafluoropropionyl (PFP) derivatives. The methyl ester $(\mathrm{Me}) \mathrm{PFP}$ derivatives $\left((\mathrm{Me})_{\mathrm{m}}-(\mathrm{PFP})_{\mathrm{n}}\right)$ obtained by this procedure (here designated as procedure A) are useful for the quantitative measurement of biological amino acids 
by GC-MS [7]. However, the carbamoyl-amino acids citrulline (Cit) and homocitrulline (hCit) (Figure 1) are converted under these reaction conditions into the methyl esters of ornithine (Orn) and lysine (Lys), respectively [7]. Analogously, glutamine (Gln) and asparagine (Asn) are converted into glutamate (Glu) and aspartate (Asp), respectively [7]. For not yet fully understood reasons, the derivatization procedure A was found to be not useful for the GC-MS analysis of $N^{\mathrm{G}}, N^{\prime} \mathrm{G}$-dimethylarginine (symmetric dimethylarginine, SDMA), in contrast to its structural isomer $N^{\mathrm{G}}, N^{\mathrm{G}}$-dimethylarginine (asymmetric dimethylarginine, ADMA) and to their precursor arginine. This difficulty was in part overcome by using a single derivatization reaction with PFPA, which most likely generates the tetrakis(pentafluoropropionyl) derivative of SDMA, i.e., SDMA-(PFP $)_{4}$ [8]. This derivatization reaction, i.e., $(\mathrm{N}, \mathrm{O})$-pentafluoroprionylation, enables quantitative measurement of SDMA in human urine, but requires the use of commercially available stable-isotope labelled SDMA analogue such as $\left[N^{\mathrm{G}}, N^{\prime} \mathrm{G}_{-}{ }^{2} \mathrm{H}_{6}\right.$ ]dimethylarginine [8] and is less sensitive compared to the GC-MS analysis of ADMA as Me-PFP derivative. Interestingly, the tripeptides glutathione and its analogue ophthalmic acid were also found to react with PFPA under the same derivatization conditions, which enabled their GC-MS analysis [9].<smiles>NC(=O)NCCC[C@H](N)C(=O)O</smiles><smiles>NC(=O)NCCCC[C@H](N)C(=O)O</smiles>

PROCEDURE A

$2 \mathrm{M} \mathrm{HCl} / \mathrm{MeOH}$

$80^{\circ} \mathrm{C}, 60 \mathrm{~min}$
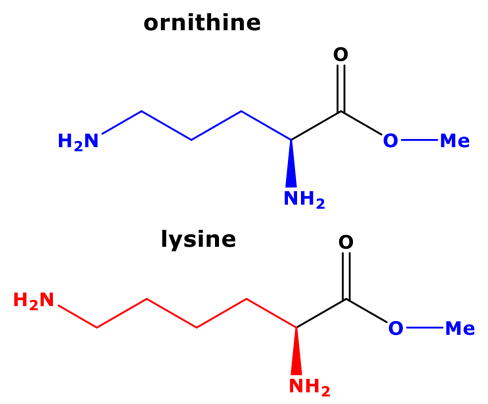

PROCEDURE B<smiles>NC(=O)NCCC[C@H](N)C(=O)O</smiles>

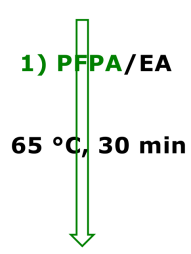<smiles>NC(=O)NCCCC[C@H](N)C(=O)O</smiles>

(2)

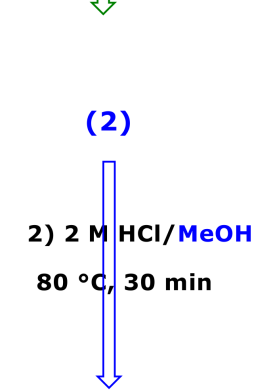

reaction products<smiles>CCCCN(CCC[C@H](NPCCC)C(=O)OC(C)C)C(=O)NCCC</smiles><smiles>CCCCN(CCCC[C@H](NC(C)C)C(=O)OCCC)C(=O)NCCC</smiles>

reaction products

Figure 1. Upper panel, procedure (A) Schematic of the reactions of citrulline and homocitrulline with $2 \mathrm{M} \mathrm{HCl} / \mathrm{MeOH}$ forming the methyl esters of ornithine and lysine, respectively. Lower panel, procedure (B) Schematic of the two-step derivatization of citrulline (left) and homocitrulline (right) first with PFPA/EA to form their PFP derivatives with the proposed formulas Cit-(PFP) $)_{4}$ and hCit-(PFP) $)_{4}$, respectively. Subsequently, these derivatives react with $2 \mathrm{M} \mathrm{HCl} / \mathrm{MeOH}$ (procedure B) to form reaction products that were characterized structurally by GC-MS in the present study. Cit, citrulline; hCit, homocitrulline; $\mathrm{MeOH}$, methanol; PFPA, pentafluoropropionic anhydride; PFP, pentafluoropropionyl residue; EA, ethyl acetate. 
The aim of the present study was to find derivatization conditions that would allow discrimination of Cit from Orn, and of hCit from Lys. Our previous observations that SDMA can be measured in human urine by GC-MS by using PFPA/EA as the first derivatization step [8] prompt us to investigate whether the derivatization of Cit and hCit with PFPA/EA as the first step may also be useful for their GC-MS analysis and for their discrimination from Orn and Lys, respectively. Analogous to SDMA, we assumed intermediate formation of Cit-(PFP $)_{4}$ and hCit-(PFP) $)_{4}$ (Figure 1). In order to investigate potential reactions of the putative intermediates, we coupled the PFPA/EA derivatization with the classical esterification with $2 \mathrm{M} \mathrm{HCl} / \mathrm{CH}_{3} \mathrm{OH}$ and with $2 \mathrm{M} \mathrm{HCl} / \mathrm{CD}_{3} \mathrm{OD}$ to prepare stable-isotopelabelled analogs of $\mathrm{Cit}$ and hCit. De facto, this resulted in a reversed order of the original two-step derivatization procedure $\mathrm{A}$, which is specified as procedure $\mathrm{B}$ in the present work (Figure 1). In most investigations using derivatization procedure B, we used experimental conditions previously found to be optimum for the derivatization and GC-MS analysis of amino acids and the tripeptides glutathione and ophthalmic acid [7-9].

\section{Materials and Methods}

\subsection{Chemicals, Materials and Reagents}

All amino acids (chemical purity, 95 to 98\%) were obtained from Sigma-Aldrich. Tetradeuterated methanol $\left(\mathrm{CD}_{3} \mathrm{OD}, 99 \%\right.$ at $\left.{ }^{2} \mathrm{H}\right)$ and pentafluoropropionic anhydride were supplied by Aldrich (Steinheim, Germany). Methanol was obtained from Chemsolute (Renningen, Germany). Hydrochloric acid (37 wt \%) was purchased from Baker (Deventer, The Netherlands). Ethyl acetate was obtained from Merck (Darmstadt, Germany). Glassware for GC-MS (1.5 mL autosampler glass vials and $0.2 \mathrm{~mL}$ microvials) and the fused-silica capillary column Optima $17(15 \mathrm{M} \times 0.25 \mathrm{~mm}$ I.D., $0.25 \mu \mathrm{M}$ film thickness $)$ were purchased from Macherey-Nagel (Düren, Germany). Separate stock solutions of amino acids were prepared by dissolving accurately weighed amounts of commercially available amino acids in deionized water. Stock solutions were diluted with deionized water as appropriate.

For the preparation of unlabelled methyl esters and deuterium-labelled methyl esters of amino acids, two derivatization reagents were prepared. To $80 \mathrm{~mL}$ ice-cold $\mathrm{CH}_{3} \mathrm{OH}$ were added $16 \mathrm{~mL}$ of $37 \mathrm{wt} \% \mathrm{HCl}$ slowly under gentle mixing. Analogously, to $80 \mathrm{~mL}$ ice-cold $\mathrm{CD}_{3} \mathrm{OD}, 16 \mathrm{~mL}$ of $37 \mathrm{wt} \% \mathrm{HCl}$ were added slowly under gentle mixing. The concentration of $\mathrm{HCl}$ in these methanolic solutions was each $2 \mathrm{M}$. In the present article, these solutions are denoted as $2 \mathrm{M} \mathrm{HCl} / \mathrm{CH}_{3} \mathrm{OH}$ and $2 \mathrm{M} \mathrm{HCl} / \mathrm{CD}_{3} \mathrm{OD}$, respectively. The PFPA-ethyl acetate reagent (PFPA/EA) was prepared daily by diluting pure PFPA in ethyl acetate (EA) $(1: 4, v / v)$.

\subsection{Derivatization Procedures $A$ and B for Amino Acids and Generation of GC-MS Spectra}

Procedure $A$. Solid amino acids were derivatized first with $2 \mathrm{M} \mathrm{HCl} / \mathrm{CH}_{3} \mathrm{OH}$ or $2 \mathrm{M}$ $\mathrm{HCl} / \mathrm{CD}_{3} \mathrm{OD}$ and then with PFPA/EA in autosampler glass vials. Briefly, residues were reconstituted in $100 \mu \mathrm{L}$ aliquots of a $2 \mathrm{M} \mathrm{HCl} / \mathrm{CH}_{3} \mathrm{OH}$ or $2 \mathrm{M} \mathrm{HCl} / \mathrm{CD}_{3} \mathrm{OD}$ solution and the glass vials were tightly sealed. Esterification was performed by heating the samples for $60 \mathrm{~min}$ at $80^{\circ} \mathrm{C}$. After cooling the samples of the esterification reaction to room temperature, solvents and reagents were evaporated to dryness under a stream of nitrogen. Aliquots $(100 \mu \mathrm{L})$ of the PFPA/EA solution were added, and the glass vials were tightly sealed and heated for $30 \mathrm{~min}$ at $65^{\circ} \mathrm{C}$ to prepare $N$-pentafluoropropionic amides of the methyl esters. Then, residues were treated first with $200 \mu \mathrm{L}$ aliquots of $400 \mathrm{mM}$ borate buffer, $\mathrm{pH} 8.5$, and immediately thereafter with $200 \mu \mathrm{L}$ aliquots of toluene, followed by immediate vortex-mixing for $60 \mathrm{~s}$ and centrifugation $\left(4000 \times g, 5 \mathrm{~min}, 18^{\circ} \mathrm{C}\right)$. Aliquots $(150 \mu \mathrm{L}) \mathrm{of}$ the upper organic phase were transferred into autosampler glass vials equipped with microinserts, and the samples were sealed and subjected to GC-MS analysis.

Procedure $B$. Solid amino acids were derivatized first with PFPA/EA $\left(30 \mathrm{~min}, 65^{\circ} \mathrm{C}\right)$ and then with $2 \mathrm{M} \mathrm{HCl} / \mathrm{CH}_{3} \mathrm{OH}$ or $2 \mathrm{M} \mathrm{HCl} / \mathrm{CD}_{3} \mathrm{OD}\left(30 \mathrm{~min}, 80^{\circ} \mathrm{C}\right)$. Briefly, aliquots $(100 \mu \mathrm{L})$ of a freshly prepared PFPA/EA solution were added, the glass vials were tightly sealed and heated for $30 \mathrm{~min}$ at $65{ }^{\circ} \mathrm{C}$ to prepare $N$-pentafluoropropionic amides of the 
methyl esters. After cooling the samples to room temperature, solvents and reagents were evaporated to dryness under a stream of nitrogen. Then, residues were reconstituted in $100 \mu \mathrm{L}$ aliquots of a $2 \mathrm{M} \mathrm{HCl} / \mathrm{CH}_{3} \mathrm{OH}$ or $2 \mathrm{M} \mathrm{HCl} / \mathrm{CD}_{3} \mathrm{OD}$ solution and the glass vials were tightly sealed. Esterification was performed by heating the samples for $30 \mathrm{~min}$ at $80{ }^{\circ} \mathrm{C}$. After cooling to room temperature, solvents and reagents were evaporated to dryness under a stream of nitrogen. Residues were treated directly with toluene $(200 \mu \mathrm{L})$, shortly vortex-mixed, aliquots $(150 \mu \mathrm{L})$ of the upper organic phase were transferred into autosampler glass vials equipped with microinserts, and the samples were sealed and subjected to GC-MS analysis.

\subsection{Generation of GC-MS Spectra}

GC-MS spectra were obtained using negative-ion chemical ionization (NICI) after separate derivatization of $5 \mathrm{nmol}$ of each amino acid using both derivatization procedures as described above. The derivatives were extracted with toluene $(1 \mathrm{~mL}), 1 \mu \mathrm{L}$ aliquots containing 5 pmol of each analyte (assuming quantitative yield) were injected in the splitless mode, and mass spectra were generated in the scan mode in the mass-to-charge $(\mathrm{m} / \mathrm{z}$ ) range 50 to 650 ( $1 \mathrm{~s}$ per scan). The GC-MS software Xcalibur and Quan Browser were used. ChemDrawProfessional 15.0 was used to draw chemical structures and to convert structures into names. GraphPad Prism 7.0 (San Diego, CA, USA) was used in statistical analyses and to prepare graphs.

\subsection{GC-MS Conditions}

All analyses were performed on a GC-MS apparatus consisting of a single quadrupole mass spectrometer model ISQ, a Trace 1210 series gas chromatograph, and an AS1310 autosampler from ThermoFisher (Dreieich, Germany). The injector temperature was kept at $280{ }^{\circ} \mathrm{C}$. Helium was used as the carrier gas at a constant flow rate of $1.0 \mathrm{~mL} / \mathrm{min}$. The oven temperature was held at $40{ }^{\circ} \mathrm{C}$ for $0.5 \mathrm{~min}$ and ramped to $210{ }^{\circ} \mathrm{C}$ at a rate of $15^{\circ} \mathrm{C} / \mathrm{min}$ and then to $320^{\circ} \mathrm{C}$ at a rate $35^{\circ} \mathrm{C} / \mathrm{min}$. Interface and ion-source temperatures were set to $300{ }^{\circ} \mathrm{C}$ and $250{ }^{\circ} \mathrm{C}$, respectively. Electron energy was $70 \mathrm{eV}$ and electron current $50 \mu \mathrm{A}$. Methane was used as the reagent gas for NICI at a constant flow rate of $2.4 \mathrm{~mL} / \mathrm{min}$. In quantitative analyses, the dwell time was $100 \mathrm{~ms}$ for each ion in the selected-ion monitoring (SIM) mode and the electron multiplier voltage was set to $1400 \mathrm{~V}$.

\section{Results}

\subsection{Derivatization of Citrulline and Structural Characterization of Its Reaction Products} by GC-MS

Scanning of the Cit samples derivatized by procedure B resulted in the elution each of six GC-MS peaks using $\mathrm{CH}_{3} \mathrm{OH}$ (Supplementary Materials Figure S1A) and $\mathrm{CD}_{3} \mathrm{OD}$ (Figure S1B). In the latter case, the peaks I, II, V, and VI eluted a few seconds in front of the peaks of the Cit sample derivatized with $\mathrm{CH}_{3} \mathrm{OH}$, indicating the presence of deuterium atoms in these peaks [7] (see Table 1). The almost identical retention times of the minor peaks III (retention time, $9.36 \mathrm{~min}$ ) and peaks IV (retention time, $9.67 \mathrm{~min}$ ) suggest that they are not methyl esters, but rather cyclic compounds.

The mass spectra of the peaks I (retention time, $8.36 \mathrm{~min}, 8.33 \mathrm{~min}$ ) contained four corresponding ions that differed by $3 \mathrm{Da}$ each, suggesting the presence of a single methylated carboxylic group (Figure S1(A1,B1)) (Table 1). A tentative structure of this molecule could be (S)-3-amino-2-oxopiperidine-1-Carboxylic acid (non-derivatized). 
Table 1. GC-MS retention times $\left(t_{\mathrm{R}}, \mathrm{min}\right)$ and most intense ions in the mass spectra of the six reaction products of citrulline derivatized with procedure B (first PFPA/EA then $2 \mathrm{M} \mathrm{HCl} / \mathrm{CH}_{3} \mathrm{OH}$ or $2 \mathrm{M}$ $\mathrm{HCl} / \mathrm{CD}_{3} \mathrm{OD}$ ). For comparison, synthetic ornithine standard (Orn-Std) was also derivatized with procedure B. See also Figure S1.

\begin{tabular}{cccc}
\hline Peak No. & $t_{\mathbf{R}}$ & Spectrum Intensity & $\boldsymbol{m} / \boldsymbol{z}$ (Intensity, \%) \\
\hline Peak I & 8.36 & $1.0 \times 10^{7}$ & $235(2), 278(5), \mathbf{2 9 8}$ a (100), 318 (2) \\
Peak I & 8.36 & $1.3 \times 10^{7}$ & $238(2), 281(4), \mathbf{3 0 1}(100), 321(1)$ \\
Peak II & 8.67 & $1.5 \times 10^{7}$ & $275(5), 398(18), \mathbf{4 1 8}(100)$ \\
Peak II & 8.65 & $1.2 \times 10^{7}$ & $278(5), 401(20), \mathbf{4 2 1}(100)$ \\
Peak III & 9.36 & $1.2 \times 10^{6}$ & $218(92), \mathbf{2 3 8}(100)$ \\
Peak III & 9.36 & $1.5 \times 10^{6}$ & $218(90), \mathbf{2 3 8}(100)$ \\
Peak IV & 9.68 & $2.8 \times 10^{6}$ & $220(20), \mathbf{2 4 0}(100), 258(5)$ \\
Peak IV & 9.67 & $3.0 \times 10^{6}$ & $220(15), \mathbf{2 4 0}(100), 258(5)$ \\
Peak V & 10.57 & $2.5 \times 10^{6}$ & $162(43), 278(15), \mathbf{2 9 8}(100), 486(2)$ \\
Peak V & 10.52 & $2.7 \times 10^{6}$ & $162(25), 281(12), 301(100), 489(6)$ \\
Peak VI & 10.75 & $2.5 \times 10^{7}$ & $290(5), 298(27), 330(100), 349(3)$ \\
Peak VI & 10.71 & $2.9 \times 10^{7}$ & $296(5), 301(25), 336(100), 355(3)$ \\
Orn-Std & 8.67 & $1.1 \times 10^{8}$ & $275(3), 398(20), \mathbf{4 1 8}(100), 437(8)$ \\
Orn-Std & 8.63 & $1.2 \times 10^{8}$ & $278(2), 401(20), \mathbf{4 2 1}(100), 440(10)$ \\
\hline aold numbers indicate mass fragments with the highest intensity in the mass spectrum (i.e., base peaks).
\end{tabular}

Derivatization of Cit by procedure B resulted in the formation of the peaks II (retention time, $8.67 \mathrm{~min}, 8.63 \mathrm{~min}$ ) (Supplementary Materials: Figure S1(A1,B1)) (Table 1). Peaks II had virtually the same mass spectra as the unlabelled Me-PFP $\left(\mathrm{d}_{0} \mathrm{Me}-\mathrm{PFP}\right)$ and the labelled Me-PFP $\left(\mathrm{d}_{3} \mathrm{Me}-\mathrm{PFP}\right)$ derivatives of Orn (Figure S1 $\left.(\mathrm{C} 1, \mathrm{C} 2)\right)$, indicating conversion of Cit to Orn by both procedures as observed previously using procedure A [7].

The mass spectra in combination with the retention times of the peaks III and the peaks IV suggest that the peak III corresponds to (S)-3-amino-4,5-dihydropyridin-2(3H)-one (Figure S1(A3,B3)) and peak IV corresponds to (S)-3-aminopiperidin-2-one (Figure S1(A4,B4)) (Table 1).

The mass spectra of the minor peaks V (retention time, $10.57 \mathrm{~min}, 10.52 \mathrm{~min}$ ) contained corresponding ions that did not differ $(m / z$ 162) or did differ by 3 Da each $(m / z, 301 / 298$; $m / z, 489 / 486)$ suggesting the presence of an intact methylated carboxylic group and presumably a fragmented methyl ester (Figure S1(A5,B5)) (Table 1). A tentative structure of this molecule could be (S)-2-amino-5-(Carboxyamino)pentanoic acid, which could be trivially named $N^{5}$-Carboxy-ornithine.

The most intense GC-MS peaks of Cit derivatized by procedure B were the peaks VI, which eluted at $10.75 \mathrm{~min}$ (using $\mathrm{CH}_{3} \mathrm{OH}$ ) and $10.71 \mathrm{~min}$ (using $\mathrm{CD}_{3} \mathrm{OD}$ ) (Figure S1(A6,B6)). The GC-MS spectra of these peaks contained several corresponding mass fragments that differed by $3 \mathrm{Da}(m / z$ 298/301) or $6 \mathrm{Da}(m / z$ 296/290, $m / z$ 336/330, $m / z$ 355/349) suggesting the presence of two carboxylic groups in these ions (Table 1 ).

\subsection{Effects of the PFPA/EA Derivatization Time in Procedure B on the Reaction Products}

The derivatization conditions used in procedure A in the present study were found to be optimal in previous studies [7,8]. In this experiment, we investigated the effect of the derivatization time of the pentafluoropropionylation reaction of Cit in procedure $\mathrm{B}$. For this, two sets of $10 \mu \mathrm{L}$ aliquots of Cit samples in distilled water (50, 100, 150, 200, $250 \mu \mathrm{M}$ ) were derivatized first with PFPA/EA at $65^{\circ} \mathrm{C}$ for $30 \mathrm{~min}$ and subsequently with $2 \mathrm{M} \mathrm{HCl} / \mathrm{CH}_{3} \mathrm{OH}$ for $10,20,30,40$, and $60 \mathrm{~min}$ at $80^{\circ} \mathrm{C}$. A $100 \mu \mathrm{M}$ Cit sample in distilled water served as internal standard and was derivatized in parallel under the same conditions using $2 \mathrm{M} \mathrm{HCl} / \mathrm{CD}_{3} \mathrm{OD}$. After toluene extraction, GC-MS analysis was performed by SIM of $m / z 298$ and $m / z 301$ for peak I, $m / z 418$ and $m / z 421$ for peak II (i.e., Orn), $m / z 298$ and $m / z 301$ for peak V, and $m / z 330$ and $m / z 336$ for peak VI (see Table 1).

The results of this experiment are illustrated in Figures $2-4$. The peak area of the internal standards varied between 11 and $16 \%(\mathrm{~m} / \mathrm{z}$ 301, Peak I), between 7 and 14\% $(\mathrm{m} / \mathrm{z} 421$, 
Peak II), between 10 and 21\% ( $\mathrm{m} / \mathrm{z}$ 301, Peak V), and between 13 and $17 \%(\mathrm{~m} / \mathrm{z} 336$, Peak $\mathrm{VI})$. There were significant time effects for all monitored internal standards $(P<0.0001$, two-way ANOVA) and a Cit concentration effect for Peak II ( $P=0.043$, two-way ANOVA). With the exception of the Peak I, the peak areas of the Peaks II, V, and VI had a minimum at the esterification time of $30 \mathrm{~min}$. When combining all data of the incubation times of the esterification, the peak area ratios $(y)$ of all peaks depended linearly upon the Cit concentration (in $\mu \mathrm{M})(x): y=-0.223+0.011 x, r^{2}=0.9943$ for Peak I, $y=0.241+0.0098 x$, $r^{2}=0.9712$ for Peak II, $y=-0.469+0.012 x, r^{2}=0.9944$ for Peak V, and $y=-0.415+0.013 x$, $r^{2}=0.9923$ for Peak VI. Linear relationships were observed between the peak area ratio (PAR) values $(y)$ of the individual peaks and the derivatized Cit concentration $(x)$ resulted in straight lines for all derivatization times of the esterification step (Figure 4). Linear regression analysis of the mean PAR of all peaks vs. The concentrations of derivatized Cit resulted in the regression equation $y=-0.217+0.0117 x, r^{2}=0.9973$. The reciprocal of the slope value of this regression equation indicates a mean concentration of $85.3 \mu \mathrm{M}$ for the sum of internal standards (nominal concentration, $100 \mu \mathrm{M}$ ).

Taken together, these results demonstrate the principle applicability of the procedure $\mathrm{B}$ for the quantitative GC-MS analysis of Cit in aqueous solutions.
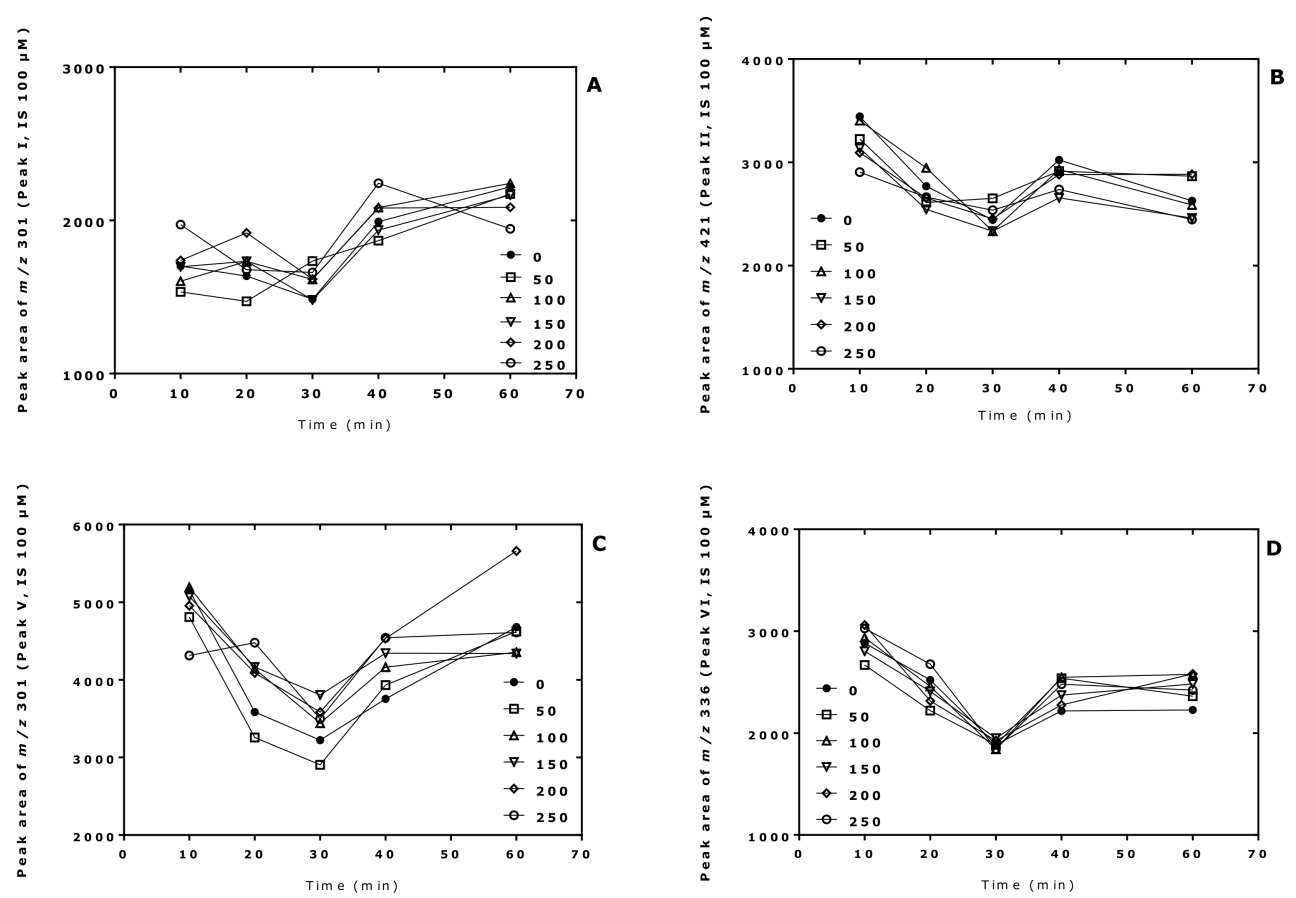

Figure 2. Time profiles of the peak areas of the internal standards (generated from $100 \mu \mathrm{M}$ Cit) upon derivatization of aqueous $\mathrm{Cit}(0,50,100,150,200,250 \mu \mathrm{M}$; see insert) using procedure B, i.e., first with PFPA/EA for a fixed time of $30 \mathrm{~min}$ at $65^{\circ} \mathrm{C}$ and subsequently with $2 \mathrm{M} \mathrm{HCl} / \mathrm{CH}_{3} \mathrm{OH}$ ( $2 \mathrm{M} \mathrm{HCl} / \mathrm{CD}_{3} \mathrm{OD}$ for the internal standards) at $80^{\circ} \mathrm{C}$ for the indicated times. (A) Peak I; (B) Peak II; (C) Peak V; (D) Peak VI. See also Table 1 and Figure 3. 

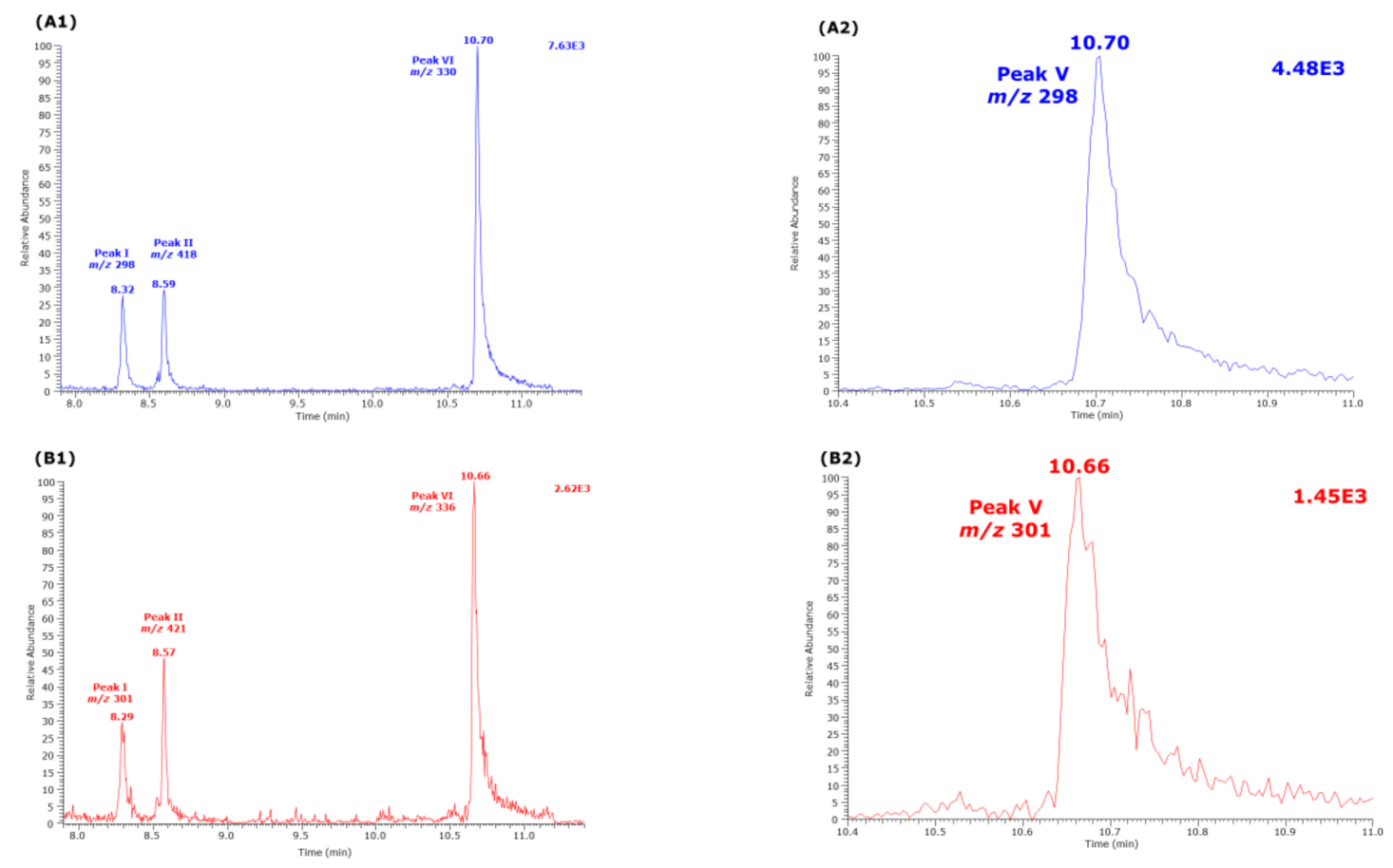

Figure 3. Partial GC-MS chromatograms from the analysis of an aqueous citrulline sample $(250 \mu \mathrm{M})$ derivatized by procedure B, i.e., first with PFPA/EA $\left(30 \mathrm{~min}, 65^{\circ} \mathrm{C}\right)$ followed with $2 \mathrm{M} \mathrm{HCl}$ in $\mathrm{CH}_{3} \mathrm{OH}$ or $\mathrm{CD}_{3} \mathrm{OD}\left(60 \mathrm{~min}, 80^{\circ} \mathrm{C}\right)$. Selected ion monitoring (SIM, $100 \mathrm{~ms}$ ) of (A1,A2) $\mathrm{m} / \mathrm{z} 298$ and $\mathrm{m} / \mathrm{z} 301$ for Peak I, $\mathrm{m} / \mathrm{z} 418$ and $\mathrm{m} / \mathrm{z} 421$ for Peak II, and $\mathrm{m} / \mathrm{z} 330$ and $m / z 336$ for Peak VI was performed. (B1,B2) SIM (100 ms) of $m / z 298$ and $m / z 301$ for Peak V. See also Table 1 and Figure 2.
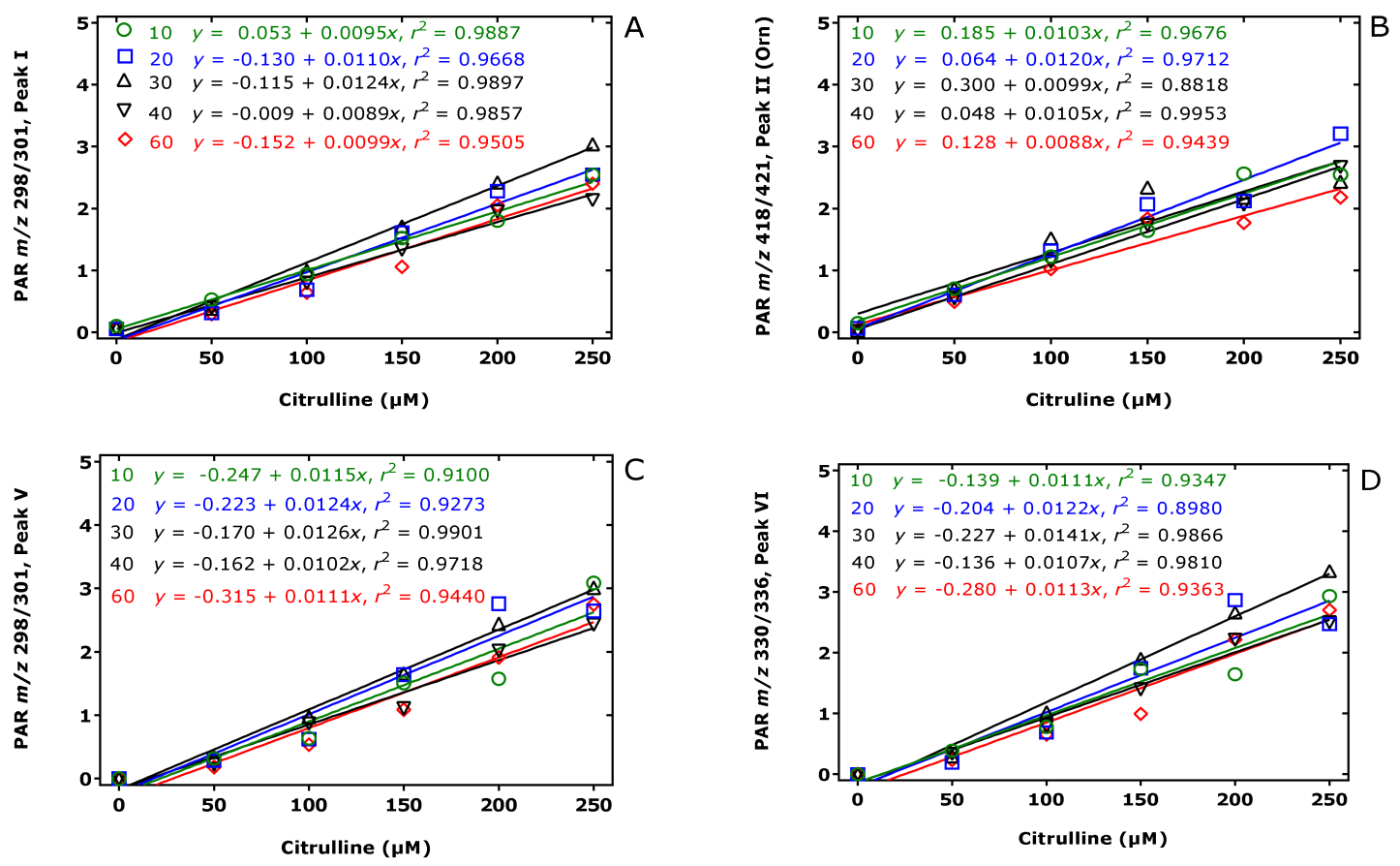

Figure 4. Linear regression analysis between the peak area ratio (PAR) values (y) for (A) Peak I, (B) Peak II, (C) Peak $\mathrm{V}$, and (D) Peak VI to the corresponding internal standards (generated from $100 \mu \mathrm{M}$ Cit) and the Cit concentration $(x)$ upon derivatization of aqueous Cit $(0,50,100,150,200,250 \mu \mathrm{M})$ first with PFPA/EA for a fixed time of $30 \mathrm{~min}$ at $65^{\circ} \mathrm{C}$ and subsequently with $2 \mathrm{M} \mathrm{HCl} / \mathrm{CH}_{3} \mathrm{OH}\left(2 \mathrm{M} \mathrm{HCl} / \mathrm{CD}_{3} \mathrm{OD}\right.$ for the internal standard) at $80{ }^{\circ} \mathrm{C}$ for 10 (green circles), 20 (blue squares), 30 (black upper triangles), 40 (black lower triangles), 60 (red diamonds) min. Insets indicate the regression equations. Note that Peak II corresponds to the Orn derivative. See also Table 1 and Figure 3. 


\subsection{Derivatization of Homocitrulline and Structural Characterization of Its Reaction Products by GC-MS}

Scanning of the hCit samples derivatized by procedure $\mathrm{B}$ resulted in the elution each of an intense GC-MS peak using $\mathrm{CH}_{3} \mathrm{OH}$ (Figure S1D) and $\mathrm{CD}_{3} \mathrm{OD}$ (Figure S1E) and two minor peaks (Table 2).

Table 2. GC-MS retention times ( $\left.t_{R}, \mathrm{~min}\right)$ and most intense ions in the mass spectra of the three reaction products of homocitrulline derivatized with procedure $\mathrm{B}$ (PFPA/EA then $2 \mathrm{M} \mathrm{HCl} / \mathrm{CH}_{3} \mathrm{OH}$ or $2 \mathrm{M} \mathrm{HCl} / \mathrm{CD}_{3} \mathrm{OD}$ ). For comparison, synthetic lysine standard (Lys-Std) was also derivatized with procedure B. See also Figure S1.

\begin{tabular}{|c|c|c|c|}
\hline Peak No. & $t_{\mathrm{R}}$ & Spectrum Intensity & $m / z$ (Intensity, \%) \\
\hline Peak I & 9.21 & $4.7 \times 10^{5}$ & $272(9), 292(5), 312^{a}(100), 338(3)$ \\
\hline Peak I & 9.18 & $5.9 \times 10^{5}$ & $272(8), 295(3), 315(100), 338(3)$ \\
\hline Peak II & 9.54 & $2.5 \times 10^{7}$ & $289(11), 392(8), 412(27), 432(100)$ \\
\hline Peak II & 9.52 & $1.1 \times 10^{7}$ & $292(10), 395(5), 415(27), 435(100)$ \\
\hline Peak III & 11.47 & $4.0 \times 10^{5}$ & $312(100), 344(42)$ \\
\hline Peak III & 11.42 & $7.7 \times 10^{5}$ & $315(100), 350(48)$ \\
\hline Lys-Std & 9.54 & $5.6 \times 10^{6}$ & $289(15), 392(16), 412(50), 432(100), 451(5)$ \\
\hline Lys-Std & 9.52 & $5.6 \times 10^{6}$ & $292(16), 395(14), 415(30), 435(100), 454(4)$ \\
\hline
\end{tabular}

a Bold numbers indicate mass fragments with the highest intensity in the mass spectrum (i.e., base peaks).

The major GC-MS peaks eluted at $9.54 \mathrm{~min}$ and $9.52 \mathrm{~min}$, respectively. The mass spectra of these peaks are very similar to those obtained from the derivatization of hCit by procedure $B$, as well as to those of the $d_{0}$ Me-PFP and $d_{3}$ Me-PFP derivatives of synthetic Lys confirming previous observations of the conversion of hCit to Lys [7] (Figure 1). The minor GC-MS peaks eluting at $9.21 \mathrm{~min}$ and $9.18 \mathrm{~min}$ could correspond to (S)-3-amino2-oxoazepane-1-Carboxylic acid (Figure S1(D1,E1)). The minor GC-MS peaks eluting at $11.47 \mathrm{~min}$ and $11.42 \mathrm{~min}$ could correspond to $\mathrm{N}^{6}$-Carboxy-lysine (Figure S1(D3,E3)), analogous to $N^{5}$-Carboxy-ornithine obtained from Cit using procedure B. The small differences in the retention times is indicative of the presence of deuterium atoms in the earlier eluting peaks.

\section{Discussion}

Procedure A allows for the reliable quantitative determination of amino acids and their metabolites in biological samples by GC-MS $[7,10]$. During the first esterification step, however, Cit and hCit undergo almost complete conversion to the methyl esters of Orn and Lys, respectively. The same happens to Gln and Asn, which are converted to the methyl esters of Glu and Asp, respectively [7]. These observations strongly indicate that the carbamide groups of $\mathrm{Cit}$, hCit, Gln, and Asn are labile under the strong esterification conditions. This circumstance prevents simultaneous measurement of Cit, Orn, hCit, Lys, Gln, Glu, Asn, and Asp [7]. We have hypothesized that reversing the order of the derivatization procedure A may present a way to prevent the abovementioned conversions. In the present study, we investigated this possibility for Cit and hCit using procedure B, i.e., first pentafluoropropionylation and subsequently esterification, using previously optimized derivatization conditions [7]. Cit and hCit reacted to form five and three reaction products, respectively. The tentative chemical structures of these reaction products are illustrated in Figure 5. 


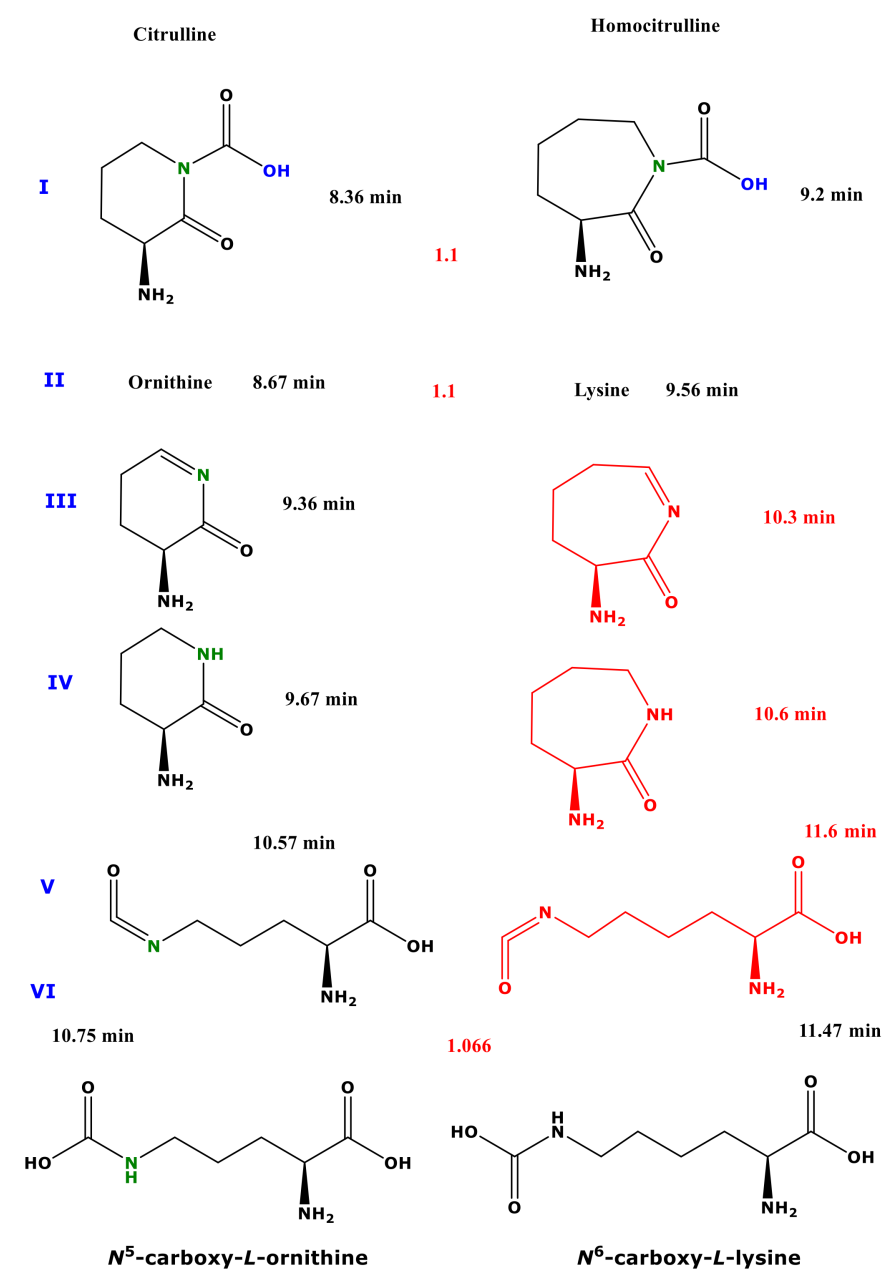

Figure 5. Proposed structures of the reaction products of citrulline (left panel) and homocitrulline (right panel) using procedure B (first PFPA/EA then $2 \mathrm{M} \mathrm{HCl} / \mathrm{MeOH}$ ). The red-marked structures were not found to be derivatization products of homocitrulline. The red numbers between the structures are the relative retention times of the homocitrulline products to the corresponding citrulline reaction products.

One major reaction product of Cit was identified as Orn. This observation suggests that pentafluoropropionylation prevents conversion of Cit to Orn, albeit not entirely. The major reaction product of hCit was identified as Lys. The reaction products of hCit corresponding to the Cit-derived peaks III, IV, and V were not observed (Figure 5). These observations suggest that pentafluoropropionylation prevents conversion of hCit to Lys to only a minor extent. The conversion of Cit to four reaction products in addition to Orn suggest that pentafluoropropionylation of Cit enables additional reactions during the second reaction step of procedure $\mathrm{B}$. The different reaction behaviour of $\mathrm{Cit}$ and hCit could be due to the longer side chain of these homologue amino acids: 3 vs. $4 \mathrm{CH}_{2}$ groups. It is assumed that this structural difference plays a major role in the formation of cyclic reaction products (Figure 5). Interestingly, procedure B resulted in the formation of $N^{5}$-Carboxy-Orn from Cit as a major reaction product and $N^{6}$-Carboxy-Lys from $\mathrm{hCit}$ as a minor reaction product. Because of the commercially unavailability of synthetic standards of $N^{5}$-Carboxy-L-Orn and $N^{6}$-Carboxy-L-Lys, we were not able to unequivocally demonstrate the formation of these reaction products. Nevertheless, these putative reaction products enable discrimination of Cit from Orn, and of hCit from Lys, respectively. It is interesting to note that the physiological occurrence and the biological significance of the free amino acids $N^{5}$-CarboxyOrn and $N^{6}$-Carboxy-Lys (Chemical Entities of Biological Interest (ChEBI):43575) have not been reported thus far. However, a $N^{6}$-Carboxy-Lys residue was found to be present 
in the active site of class $D \beta$-lactamases and to play a significant role in the hydrolysis of $\beta$-lactam antibiotics $[11,12]$. Our study provides useful information for forthcoming studies on these uncommon amino acids.

Based on the results of our study, we propose potential mechanisms that may explain the reaction products of Cit and hCit during the derivatization procedure B. Being a highly reactive derivatization reagent, PFPA is likely to react with all functional groups of free amino acids and those in tripeptides [8,9]. We therefore assume that PFPA/EA reacts with all functional groups of $\mathrm{Cit}$ to form its $\mathrm{N}, \mathrm{N}, \mathrm{N}, \mathrm{O}-(\mathrm{PFP})_{4}$ derivative (Figure 6). An intact Cit-(PFP $)_{4}$ derivative was not observed in our study. An explanation could be that the remaining Cit-(PFP) ${ }_{4}$ extracted into toluene decomposed during the injection in the hot injector $\left(280^{\circ} \mathrm{C}\right)$. This is more likely to happen to the O-PFP residue, as $\mathrm{N}$-PFP residues of derivatized amino acids are considerably stable [7]. A more plausible explanation for our observations is that the O-PFP residue of the Cit derivative is a mixed anhydride of PFPA and the carboxylic group Cit. As such, the Cit-(PFP) $)_{4}$ derivative is likely to undergo several reactions with $2 \mathrm{M} \mathrm{HCl} / \mathrm{CH}_{3} \mathrm{OH}$ (Figure 6). The reaction of the Cit$(\mathrm{PFP})_{4}$ derivative with $2 \mathrm{M} \mathrm{HCl} / \mathrm{CH}_{3} \mathrm{OH}$ will always generate its $C^{1}$-Carboxy-methyl ester. Analogously, the reaction of the Cit-(PFP) $)_{4}$ derivative with $2 \mathrm{M} \mathrm{HCl} / \mathrm{CD}_{3} \mathrm{OD}$ will generate the $C^{1}$-Carboxy-trideutero-methyl ester. This provides a way to prepare deuterium-labelled internal standards for quantitative analyses. Especially the N-PFP residue on the carbamide functionality of the Cit-(PFP $)_{4}$ derivative opens ways for additional reactions, which leads to the formation of open reaction products including $N^{5}$-Carboxy-Orn from Cit and $N^{6}$ Carboxy-Lys from hCit and several cyclic reaction products that can be utilized both in analytical and organic preparative chemistry (Figure 6).

The reaction time of the esterification reaction performed at $80^{\circ} \mathrm{C}$ has an effect on the yield of individual reaction products. In a proof-of-principle experiment, we found that procedure $B$ is useful for the quantitative analysis of Cit in aqueous solution for several esterification times. Yet, the quantitative determination of Cit, Orn, hCit, and Lys in biological samples by GC-MS using procedure B remains to be optimized and validated. Our preliminary studies suggest that the derivatization procedure $B$ can be extended to Gln and Asn, which are converted into Glu and Asp, respectively. The derivatization procedure $\mathrm{B}$ possess the potential to simultaneously quantitate a large number of biological amino acids and their metabolites by GC-MS using in situ prepared $\left(\mathrm{d}_{3} \mathrm{Me}\right)_{\mathrm{m}}-(\mathrm{PFP})_{\mathrm{n}}$ or commercially available stable-isotope labelled amino acids as internal standards. 


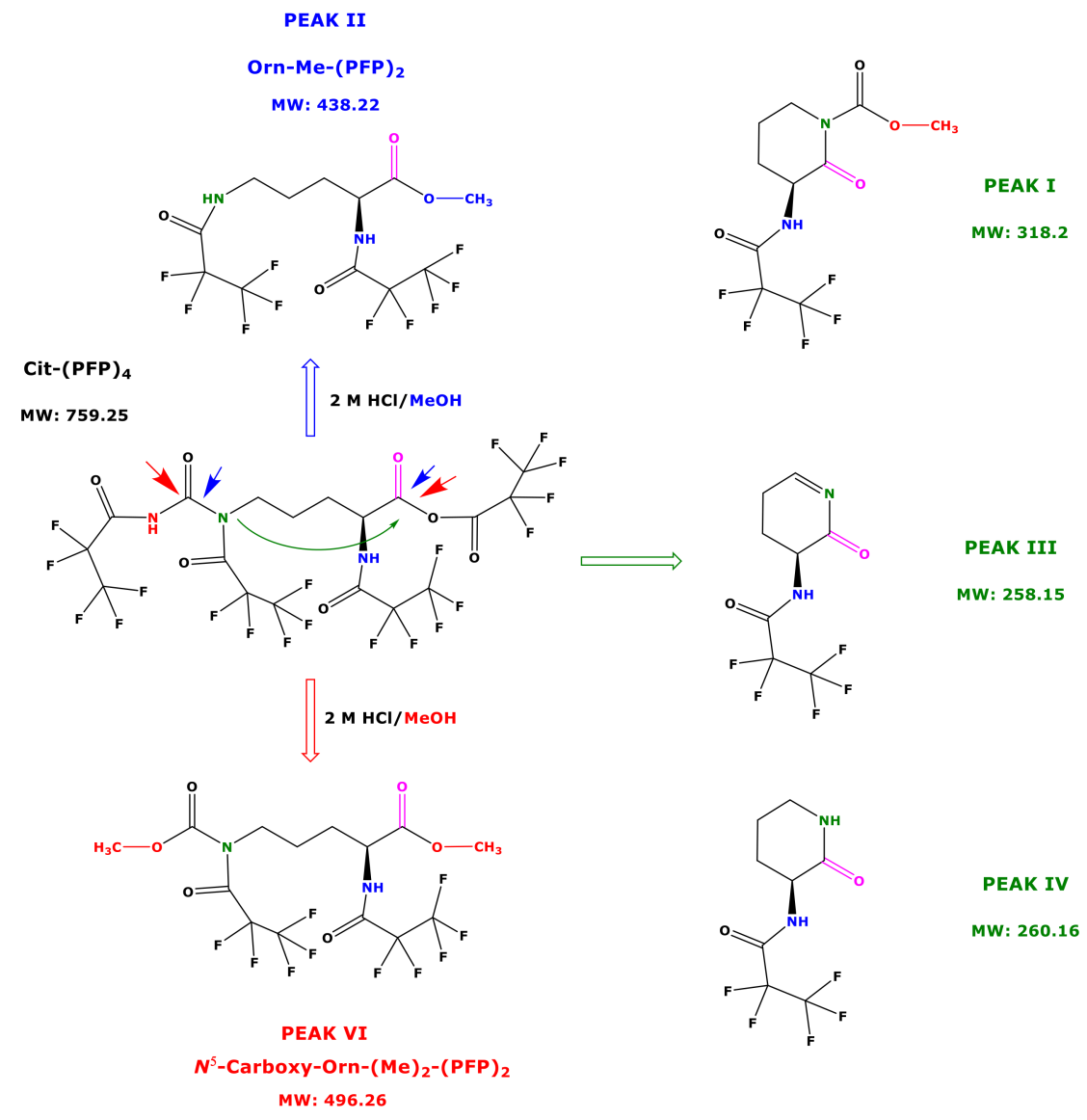

Figure 6. Proposed reaction products of the very first, not yet identified $N, N, N, O-(\mathrm{PFP})_{4}$ derivative of Cit using procedure B. Blue and red arrows indicate the carbonyl moieties, which are attacked by methanol, and the green arrow indicates the intramolecular attack of $N^{5}$ on $C^{1}$ carbonyl group.

Supplementary Materials: The following are available online, Figure S1: Separate derivatization of citrulline and homocitrulline $(5 \mathrm{nmol}$ each) by procedure $\mathrm{B}$, i.e., first with PFPA/EA and then $2 \mathrm{M} \mathrm{HCl} / \mathrm{CH}_{3} \mathrm{OH}$ or $2 \mathrm{M} \mathrm{HCl} / \mathrm{CD}_{3} \mathrm{OD}$, and structural characterization of their reaction products by GC-MS.

Author Contributions: Conceptualization, D.T.; methodology, S.B.; software, S.B. and D.T.; validation, S.B., A.B. and D.T.; formal analysis, D.T.; investigation, S.B. and A.B.; resources, D.T.; data curation, S.B. and D.T. writing-original draft preparation, D.T., S.B. and A.B.; writing, S.B., A.B. and D.T.; visualization, S.B. and D.T.; supervision, D.T.; project administration, D.T.; funding acquisition, D.T. All authors have read and agreed to the published version of the manuscript.

Funding: This research received no external funding.

Institutional Review Board Statement: Ethical review and approval were waived for this study, due to the use of human urine samples originally collected in previously ethically approved study.

Informed Consent Statement: Subject consent was waived due to the use of human urine samples originally collected in previously ethically approved study.

Data Availability Statement: The study did not report any data.

Acknowledgments: We thank Bibiana Beckmann for administrative assistance.

Conflicts of Interest: The authors declare no conflict of interest.

Sample Availability: Samples of the compounds are not available from the authors. 


\section{References}

1. Hušek, P.; Macek, K. Gas chromatography of amino acids. J. Chromatogr. A 1975, 113, 139-230. [CrossRef]

2. Hušek, P.; Švagera, Z.; Hanzlíková, D.; Řimnáčová, L.; Zahradníčková, H.; Opekarová, I.; Šimek, P. Profiling of urinary aminocarboxylic metabolites by in-situ heptafluorobutyl chloroformate mediated sample preparation and gas-mass spectrometry. J. Chromatogr. A 2016, 1443, 211-232. [CrossRef] [PubMed]

3. Ferré, S.; González-Ruiz, V.; Guillarme, D.; Rudaz, S. Analytical strategies for the determination of amino acids: Past, present and future trends. J. Chromatogr. B Analyt. Technol. Biomed. Life Sci. 2019, 1132, 121819. [CrossRef] [PubMed]

4. Xu, W.; Zhong, C.; Zou, C.; Wang, B.; Zhang, N. Analytical methods for amino acid determination in organisms. Amino Acids 2020, 52, 1071-1088. [CrossRef] [PubMed]

5. Zhao, L.; Ni, Y.; Su, M.; Li, H.; Dong, F.; Chen, W.; Wei, R.; Zhang, L.; Guiraud, S.P.; Martin, F.P.; et al. High Throughput and Quantitative Measurement of Microbial Metabolome by Gas Chromatography/Mass Spectrometry Using Automated Alkyl Chloroformate Derivatization. Anal. Chem. 2017, 89, 5565-5577. [CrossRef] [PubMed]

6. Baskal, S.; Bollenbach, A.; Tsikas, D. Two-step derivatization of amino acids for stable-isotope dilution GC-MS analysis: Long-term stability of methyl ester-pentafluoropropionic derivatives in toluene extracts. Molecules 2021, 26, 1726. [CrossRef] [PubMed]

7. Hanff, E.; Ruben, S.; Kreuzer, M.; Bollenbach, A.; Kayacelebi, A.A.; Das, A.M.; von Versen-Höynck, F.; von Kaisenberg, C.; Haffner, D.; Ückert, S.; et al. Development and validation of GC-MS methods for the comprehensive analysis of amino acids in plasma and urine and applications to the HELLP syndrome and pediatric kidney transplantation: Evidence of altered methylation, transamidination, and arginase activity. Amino Acids 2019, 51, 529-547. [CrossRef] [PubMed]

8. Bollenbach, A.; Hanff, E.; Beckmann, B.; Kruger, R.; Tsikas, D. GC-MS quantification of urinary symmetric dimethylarginine (SDMA), a whole-body symmetric L-arginine methylation index. Anal. Biochem. 2018, 556, 40-44. [CrossRef] [PubMed]

9. Bollenbach, A.; Tsikas, D. Measurement of the tripeptides glutathione and ophthalmic acid by gas chromatography-mass spectrometry. Anal. Biochem. 2020, 113841. [CrossRef] [PubMed]

10. Tsikas, D. De novo synthesis of trideuteromethyl esters of amino acids for use in GC-MS and GC-tandem MS exemplified for ADMA in human plasma and urine: Standardization, validation, comparison and proof of evidence for their aptitude as internal standards. J. Chromatogr. B 2009, 877, 2308-2320. [CrossRef] [PubMed]

11. Schneider, K.D.; Bethel, C.R.; Distler, A.M.; Hujer, A.M.; Bonomo, R.A.; Leonard, D.A. Mutation of the active site carboxy-lysine (K70) of OXA-1 beta-lactamase results in a deacylation-deficient enzyme. Biochemistry 2009, 48, 6136-6145. [CrossRef] [PubMed]

12. Leonard, D.A.; Bonomo, R.A.; Powers, R.A. Class D $\beta$-lactamases: A reappraisal after five decades. Acc. Chem. Res. 2013, 46, 2407-2415. [CrossRef] [PubMed] 